\title{
ALTYAPI YATIRIM KARARLARINDA MALİYET HESABI VE ETKİSİNE DAİR BİR İNCELEME
}

\author{
Selim PAZARÇEVIREN ${ }^{*}$, Mehmet Çağrı KIZILTAȘ ${ }^{2}$
}

1İstanbul Ticaret Üniversitesi, İșletme Fakültesi, Muhasebe ve Denetim Bölümü, İstanbul, Türkiye 2İstanbul Ticaret Üniversitesi, Mühendislik Fakültesi, İnşaat Mühendisliği Bölümü, İstanbul, Türkiye

\begin{tabular}{|c|c|}
\hline Anahtar Kelimeler & Öz \\
\hline $\begin{array}{l}\text { Altyapı, } \\
\text { Maliyet, } \\
\text { Proje, } \\
\text { Inşaat, } \\
\text { Verimlilik. }\end{array}$ & 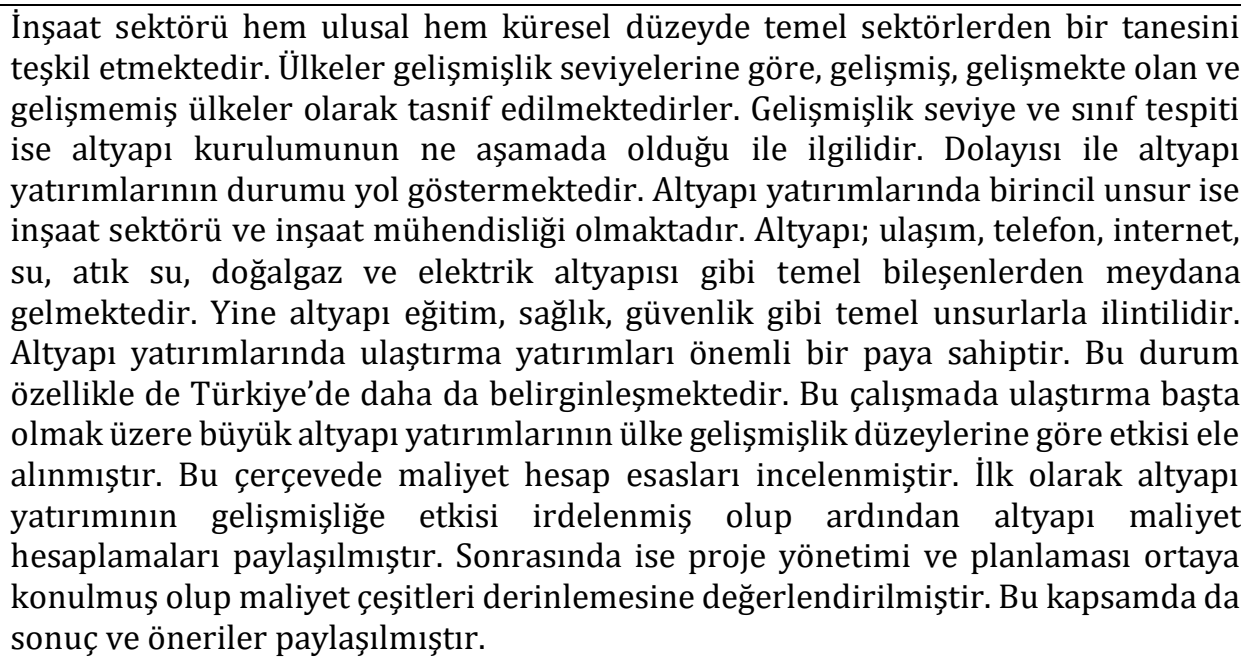 \\
\hline
\end{tabular}

\section{A REVIEW OF COST EFFECT AND CALCULATIONS ON INFRASTRUCTURAL INVESTMENT DECISIONS}

\section{Keywords}

Infrastructure,

Cost,

Project,

Construction,

Efficiency.

\begin{abstract}
Civil engineering sector is one of the main sectors both on national and global scale. Countries are classified in terms of their development levels as developed, developing and undeveloped countries. Specifying of developing level and class is correlated with infrastructural establishing period. Thus infrastructural investment case is enlightening at this point. First parameter in infrastructure investment is civil engineering sector. Infrastructure constitutes of main elements as transport, phone, internet, water, waste water, naturel gas and electrical infrastructure. Also infrastructure is related with education, health security main parameters. Transportation investments have an important share on infrastructural investments. This case is especially more clear in Turkey. In this paper effects of huge infrastructural investments especially transportation in terms of development levels of countries are revealed. In this framework cost calculation essentials are reviewed. Firstly, effect to developing of infrastructure investment is expressed that infrastructural cost analysis are shared. After these project management and planning are executed and cost sorts are evaluated in deeply. On this context conclusions and recommendations are shared.
\end{abstract}

\section{Alıntı / Cite}

Pazarceviren, S., Kızıltaş, M.Ç., (2021). Altyapı Yatırım Kararlarında Maliyet Hesabı ve Etkisine Dair Bir İnceleme, Mühendislik Bilimleri ve Tasarım Dergisi, 9(1), 348-358.

Yazar Kimliği / Author ID (ORCID Number)

S. Pazarçeviren, 0000-0001-8198-4424

M. Ç. Kızılttaş, 0000-0001-9852-9428

\begin{tabular}{l} 
Makale Süreci / Article Process \\
Başvuru Tarihi / Submission Date \\
Revizyon Tarihi / Revision Date \\
Kabul Tarihi / Accepted Date \\
Yayım Tarihi / Published Date \\
\hline
\end{tabular}

22.10 .2020

19.02 .2021

19.02.2021

30.03.2021

\footnotetext{
* ilgili yazar / Corresponding author: spazarceviren@ticaret.edu.tr
} 


\section{Giriş (Introduction)}

Ülkeler gelişmişlik düzeylerine göre; gelişmiş ülkeler, gelişmekte olan ülkeler, gelişmemiş ülkeler olarak tasnif edilmektedir. Altyapı yatırımları gelişmişlik düzeyinde önemli bir etken ve gösterge niteliğinde olmaktadır. Gelișmemiş olan ülkelerde altyapı yatırımlarının yıllık bütçeden aldığı pay azdır. Gelișmiş ülkelerde de altyapı yatırımlarının payı indirgenmiş bir düzeydedir. Ancak gelişmekte olan ülkelerde altyapı yatırımlarının yıllık bütçeden aldığı pay oldukça yüksektir. Zira bu ülkelerde ekonomik büyüme ve nüfusu hareketliliği had safhadadır, bu da altyapı talebini ve kurulum sürecini tetiklemektedir. Türkiye de gelişmekte olan bir ülkedir, hummalı bir altyapı teşekkülü devam etmekte olup öte yandan ulaştırma yatırımlarının altyapı yatırımları içerisinde aldığı paylar her yıl oldukça yüksek seviyelerde seyretmektedir.

Ulaştırma, inşaat mühendisliğinin bir alt unsurudur. İnşaat mühendisliği kamuda sanılandan çok daha geniş bir içeriği ihtiva etmektedir. Kamudaki algı esasen sadece konutlar ve yüksek katlı-uzun açıklıklı yapıları içermektedir. Bununla birlikte inşaat mühendisliği esasen su yapılarını, zemin disiplinini, üstyapıları, altyapıları, ulaştırmayı ve bunların işletimini içermektedir. Bu da kentteki hemen her şeyin doğrudan ya doğrudan olmayan bir şekilde inşaat mühendisliğinin konusu olduğu anlamına gelmektedir. Ulaştırma yatırımları aynı zamanda inşaat yatırımlarıdır. Türkiye'deki konut, gökdelen ve alışveriş merkezi gibi yapıların ivmeli yapılandırılma süreci de dikkate alındığında toplamda ne kadar devasa büyüklükte bir ana sektörle karşı karşıya olunduğu daha iyi anlaşılacaktır. Dolayısı ile söz konusu devasa sektördeki bütün proje, projeksiyon, planlama, programlama, inşa, işletim ve sonlandırma süreçlerinin fayda maliyet analizlerinin son derece dikkatli, elverişli ve gelişmiş bir şekilde gerçekleştirilmesi gerekliliği açıktır.

İnşaat sektörü, Türkiye'deki en belirleyici sektörlerden birisini teșkil etmektedir. Türkiye inşaat müteahhitliğinde dünya genelinde Çin ve Amerika Birleşik Devletleri (ABD) ile birlikte en büyükler arasında yer almaktadır. Yine İspanya da bu konuda etkindir. Türkiye; Libya, Suudi Arabistan, Katar, Birleşik Arap Emirlikleri (BAE), Irak, Rusya, Orta Asya, Balkanlar başta olmak üzere inşaat sektöründe pek çok ülkede yatırımları ile birlikte etkin konumdadır. Yine Türkiye'nin Pakistan, Meksika, Ukrayna, Cezayir, Tunus, Sudan, Somali gibi ülkelerde etkin olması da beklenebilecek bir durumdur. Türkiye'de hâlihazırda büyük yerli inşaat şirketleri ya milli devasa altyapı projelerinin konsorsiyumlarında yer almakta ya da büyük yatırımlarını yurtdışında yapmaktadır. İnşaat maliyetleri inşaat şirketlerinin performansı ve yol haritaları konusunda ana belirleyicilerden birisi olup Şelik 1'de güncel birim inşaat değerleri verilmektedir.

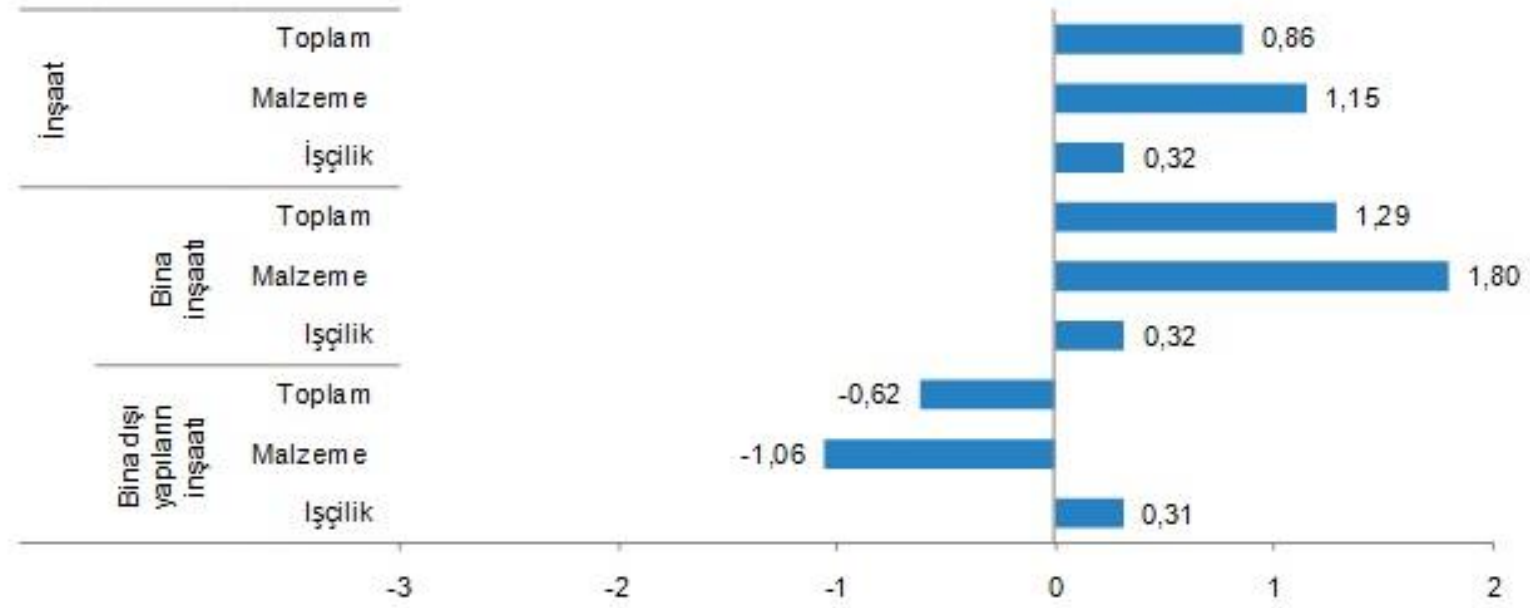

Şekil 1. İnşaat Maliyet Endeksi Aylık Değişim Oranları (\%), (Construction Cost Index Monthly Change Rates) Nisan 2020, (TÜİK 2020) 


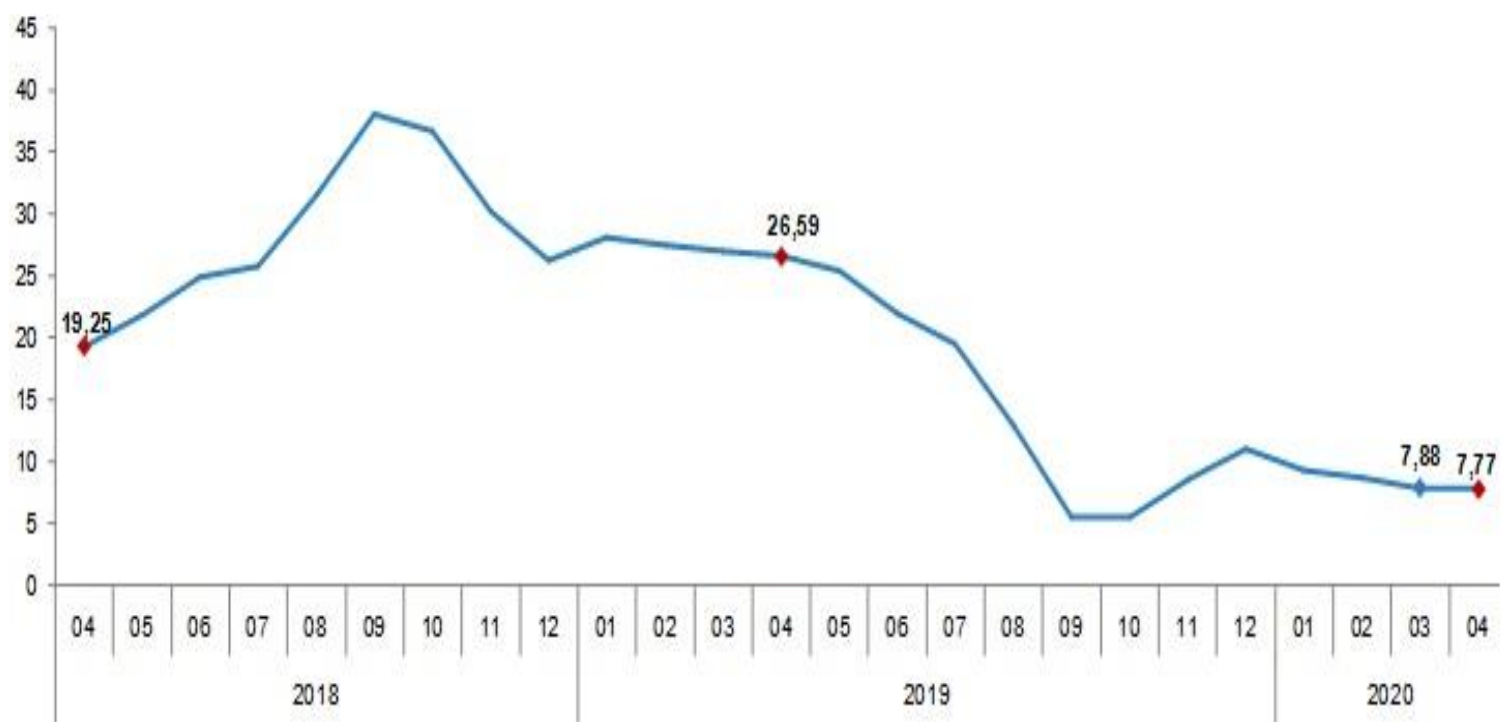

Şekil 2. Bina İnşaatı Maliyet Endeksi Yıllık Değişim Oranı (\%) (Building Construct Cost Index Yearly Change Rates), Nisan 2020 (TÜíK 2020)

Şekil 2'de ise bu söz konusu değerlerin binalara münhasır değerleri gösterilmektedir. Ulaştırma inşaat mühendisliğinin önemli bir kısmını teşkil etmektedir. Altyapı içinde de ulaştırma yatırımlarının payı büyüktür. Altyapı da kent de doğrudan ya da dolaylı olarak bütünü ile inşaat sektörünün konusudur. Kamuda bilinen inşaat mühendisliği ve müteahhitliği esasen sadece gerçekte olanın bir bölümü olup yapı ana bilim dalı dâhilinde telakki edilmektedir. Yapı ana bilim dalında konut, yüksek katlı binalar ve uzun açıklıklı binaları ihtiva etmektedir. Altyapı fayda maliyet analizleri; açık bir fiyatlandırma hesabını gerektirmektedir. Genelleștirilmiş seyahat maliyetinin önemli bir unsuru ise ödenecek olan ortalama ücrettir. Üretici maliyetleri (altyapı ve işletim) temelde karayolu ve havayolunda üretilen seyahat maliyetlerini içermektedir (10.Kalkınma Planı, 2012). Altyapının inşası, 3 ana maliyet tipini içermekte olup bunlar planlama ve arazi maliyetleri, altyapı yapım maliyetleri ve üstyapı maliyetleridir. Fizibilite çalışmaları, teknik tasarım, arazi alımı, yasal ve idari ödemeler, lisanslar ve izinler vs. planlama ve arazi maliyetlerine dâhil olmakta olup maliyetli arazi kamulaştırmaları gerektiren yeni demiryolu hatlarındaki toplam altyapı maliyetlerinin \%10'una ulaşabilmektedir. Altyapı yapım maliyetleri; arazi tesviyesi ve platform yapılmasını içermektedir. Arazi özelliklerine bağlı olarak toplam yatırım maliyetinin \%15'i ila \%50'sini teşkil eden maliyetler dahilinde viyadük, köprü ve tünel inşası gereksinimi ortaya çıkabilir. Nihai olarak da üstyapı maliyetleri olarak adlandırlan raylar, hat boyu kaplama, sinyal sistemleri, katener dizisi, elektrifikasyon, iletişim ve güvenlik ekipmanları gibi demiryollarının belirli unsurlarına da gereksinim olabilir (Ilıcalı vd., 2014).

\section{Fayda Maliyet Değerlendirmeleri (Benefit Cost Evaluations)}

Altyapı yatırımlarında, gelişmekte olan ülkelerde, özellikle de Türkiye’de hummalı bir yatırım süreci olduğu bilinmektedir. Bu bağlamda oldukça kapsayıcı ve muhtevalı olan altyapıda maliyetin hesabına dair kesin ve güvenilir bilgiler olduğu takdirde kayda değer bir öngörü geliştirilebilecektir. Bu açıdan başlangıç maliyeti yaklaşımı ile işlem yürütülmekte olup aktarmalar ihmal edilmekte sureti ile net fayda ve net maliyet değişimleri ele alınmaktadır. Yüksek hızlı demiryolu (YHD) yatırımının sosyal karlılığı aşağıdaki koşulların yerine getirilmesini gerektirmektedir:

$$
{ }_{0} \int^{T} B(Q) e^{-(r-g) t} d t>I+{ }_{0}{ }^{T} C_{f} e^{-r t} d t+{ }_{0} \int^{T} C_{q}(Q) e^{-(r-g) t} d t
$$

Burada;

$\mathrm{B}(\mathrm{Q})=$ Projenin ylllı sosyal faydası

$\mathrm{C}_{\mathrm{f}}=$ Yılllk sabit bakım ve işletim maliyeti

$C_{q}(Q)=Q^{\prime}$ ya bağlı yıllık bakım ve işletim maliyeti

$\mathrm{Q}=$ Yolculuk sayısı

$\mathrm{I}=$ Yatırım maliyetleri

$\mathrm{T}=$ Proje ömrü

$\mathrm{t}=\mathrm{Yl}$

$\mathrm{r}=$ İskonto oranı

$\mathrm{g}=$ Fayda ve maliyetlerin yıllık büyümesi 
B(Q) konvansiyonel bir ulaştırma türünün işletildiği bir yerdeki değerlendirmeye konu bir koridorda yüksek hızlı demiryolu (YHD) işletiminin başlamasının yıllık kişi başı sosyal faydasıdır. B(Q)'nun ana unsurları ise; saptırılan trafik kaynaklı zaman ve maliyet tasarrufları, kalitedeki artış, üretilen seyahat, dışsallıklardaki düşüş ve genelde özellikle de diğer ulaștırma türleri (konvansiyonel ulaștırma türü) üzerindeki etkiler dâhil olmak üzere ikincil pazarlardaki ilgili dolaylı etkilerdir. Bölgesel dengesizliklerin ve ekonomik etkinliklerin yeniden dağılımı ile ilgili diğer faydalar B(Q)'da yer almamaktadır. Denklem (1)'de yer alan faydaların net şimdiki değeri aşağıdaki gibi çözümlenebilir:

$$
{ }_{0} \int^{T} B(Q) e^{-(r-g) t} d t={ }_{0}{ }^{T}\left[V\left(T_{0}-T_{1}\right) Q_{0}+C_{C}\right](1+\alpha) e^{-(r-g) t} d t+\sum_{i=1} N_{0} \int{ }^{T} \delta_{i}\left(q_{i}{ }^{1}-q_{i}{ }^{0}\right) e^{-(r-g) t} d t
$$

Burada;

V = Zamanın ortalama değeri (hizmet kalitesindeki farkları içermektedir)

$T_{0}=$ Proje olmadığı durumda yolculuk başına ortalama kullanıcı süresi

$\mathrm{T}_{1}=$ Proje olan durumda yolculuk başına ortalama kullanıcı süresi

$\mathrm{Q}_{0}=$ Yüksek hızlı demiryollarına ilk yılda saptırılan trafik

$\mathrm{C}_{\mathrm{C}}=$ Konvansiyonel türün yıllık değişim maliyeti

$\alpha=Q_{0}$ 'a nazaran proje dâhilinde üretilen yolculuk oranı

$\delta_{\mathrm{i}}=\mathrm{i}$ pazarındaki bozulma

$\mathrm{q}_{\mathrm{i}}{ }^{0}=$ Proje olmadığ durumda i pazarındaki denge talebi

$\mathrm{q}_{\mathrm{i}}{ }^{1}=$ Proje olduğu durumda i pazarındaki denge talebi

Denklem (2) alternatif ulaştırma işletimcilerinin başa baş pozisyonda olduğu ve üretilen yolculukların ortalama kişi bașı faydasının saptırılan yolculuk değerlerine eşit olduğu kabul edilmektedir. Denklem (2)'nin Denklem (1)'de yerini koyulması yolu ile (2) nolu denklemin çözümündeki son terim olan dolaylı etkilerin sıfıra eşit olduğu kabulü ile pozitif bir net şimdiki değer için gerekinim duyulan talebin başlangıç hacminin hesaplanabilmesi adına bu durum olası hale gelmektedir.

Kabuller şu şekildedir: doğrudan olmayan etkiler (pozitif ve negatif) kümeli modelde iptal edilmiştir, hariciliklerdeki net düşüşler ihmal edilebilirdir, ilk yıl net faydaları proje ömrü boyunca sabit bir yıllık oranla artmaktadır, üretici fazlalıkları alternatif türlerde değişmemektedir, pazar fiyatları fırsat maliyetlerine eşittir ve zaman tasarrufları, kalite gelişimi ve üretilen yolculuklar için gözden çıkarılan ödeme haricinde kullanıcılar için başka herhangi bir fayda bulunmamaktadır. Ardından ise pozitif bir net şimdiki değer için gerekli koşul aşağıdaki gibi açılkanabilir:

$$
{ }_{0} \int^{\mathrm{T}}\left[\mathrm{B}(\mathrm{Q})-\mathrm{C}_{\mathrm{q}}(\mathrm{Q})\right] \mathrm{e}^{-(\mathrm{r}-\mathrm{g}) \mathrm{t}} \mathrm{dt}-{ }_{0} \int^{\mathrm{T}} \mathrm{C}_{\mathrm{f}} \mathrm{e}^{-\mathrm{rt}} \mathrm{dt}>\mathrm{I}
$$

Burada;

$\mathrm{B}(\mathrm{Q})=$ Projenin yıllık sosyal faydası

$\mathrm{C}_{\mathrm{q}}(\mathrm{Q})=$ Projenin Q'ya göre değişen yıllık bakım ve işletim maliyeti

$\mathrm{C}_{\mathrm{f}}=$ Yıllık sabit bakım ve işletim maliyeti

I = Yatırım maliyetleri

$\mathrm{T}=$ Proje ömrü

$r=$ Sosyal iskonto oranı

$\mathrm{g}=$ Fayda ve maliyetlerdeki yıllık artış

r > g kabulü ve projenin sosyal cazibesi için Denklem (3)'ün çözülmesi dahilinde aşağıdaki denklem elde edilmektedir:

$$
\left.\left[\left(B(Q)-C_{q}(Q)\right) / r-g\right)\right]^{*}\left[1-e^{-(r-g) T}\right]-\left[\left(C_{f} / r\right) *\left(1-e^{-r T}\right)\right]>I
$$

Bütün denklem taraflarının I ile bölünmesi ile terimler yeniden düzenlenerek aşağıdaki Denklem (5) elde edilmektedir:

$$
\left.\left[\left(\mathrm{B}(\mathrm{Q})-\mathrm{C}_{\mathrm{q}}(\mathrm{Q})\right) / \mathrm{I}\right)\right]>\left[\left(\mathrm{r}-\mathrm{g} / 1-\mathrm{e}^{-(\mathrm{r}-\mathrm{g}) \mathrm{T}}\right)\right]+\left[\left(\mathrm{C}_{\mathrm{f}} / \mathrm{I}\right)^{*}(\mathrm{r}-\mathrm{g}) /(\mathrm{r})^{*}\left(1-\mathrm{e}^{-\mathrm{rT}}\right) /\left(1-\mathrm{e}^{-(\mathrm{r}-\mathrm{g})^{\mathrm{T}}}\right)\right]
$$

Denklem (5)'in ekonomik yorumu oldukça sezgisel olup projenin hizmet ömrü oldukça uzundur (T sonsuza doğru uzamaktadır). Bu durumda ilk yılın net faydaları (yılık faydalardan Q’ya bağlı değişken maliyetlerin çıkarılması) yatırım maliyetlerinin bir oranı olarak açıklanmakta olup, yıllık sabit bakım maliyetlerinin oranı (r-g/r) ile net faydaların büyüme oranının toplamının sosyal iskonto oranından düşülmesinde daha büyük bir değer olmalıdır. Bir sonlu proje ömrü durumunda ise tek değişim, karlılık için daha yüksek talep kıstası olmaktadır (Liu vd., 2007). Dışsallıklar ve doğrudan olmayan etkiler önemli olmadığında ilk yıl ki yıllık faydalar (B(Q)-C $\left.C_{q}(Q)\right)$ genel olarak; zaman tasarrufları, artan trafik ile net değişken maliyetler ve üretilen trafikten kaynaklı maliyetlerden ortaya çlkmaktadır. 


\section{Materyal ve Yöntem (Material and Method)}

Söz konusu net faydalar; hizmetlendirilen talebin hacmine, hâlihazırdaki ulaştırma türlerine nispetle hattaki zaman tasarrufları ve kullanıcının ortalama zaman değerine bağlı olmaktadır (Rawat vd., 2015). Tipik inşa ve işletim maliyetleri, zaman tasarrufu, zamanın değeri, faydaların yıllık artışı ve sosyal iskonto oranı dâhilindeki sonuçlar göstermektedir ki sosyal fayda terimlerine göre uyarlanması gereken yeni bir yatırım için kritik eşik söz konusu olmaktadır. Dolayısıyla bu anlamda ulaştırma yatırımlarını operasyonel seviyedeki ulaştırma yatırımları, taktik seviyedeki ulaştırma yatırımları ve stratejik seviyedeki ulaştırma yatırımları olarak değerlendirmek mümkündür. Bu, lojistikteki tedarik zincirindeki mantığa paralel olarak Şekil 3'de gösterildiği gibi açıklanabilir. Şekil 3'de görüldüğü üzere Operasyonel Seviye, kısa vadeli ve sonuç odaklı olup en net verinin teminine dayalı olarak diğerlerine nazaran en kısa proses süreci ile sonlandırılır. Taktik Seviye; daha genel ve daha geniş çaptaki verilerin daha uzun erimli bir süreçte toplanarak işlenmesine dayalıdır ve orta vadeli bir planlamayı gerektirir. Stratejik Seviye ise en uzun erimli çalışmayı gerektirendir, en geniş aralıkta ve en yorumlanmayı gerektiren verilerin toplanması içermektedir.

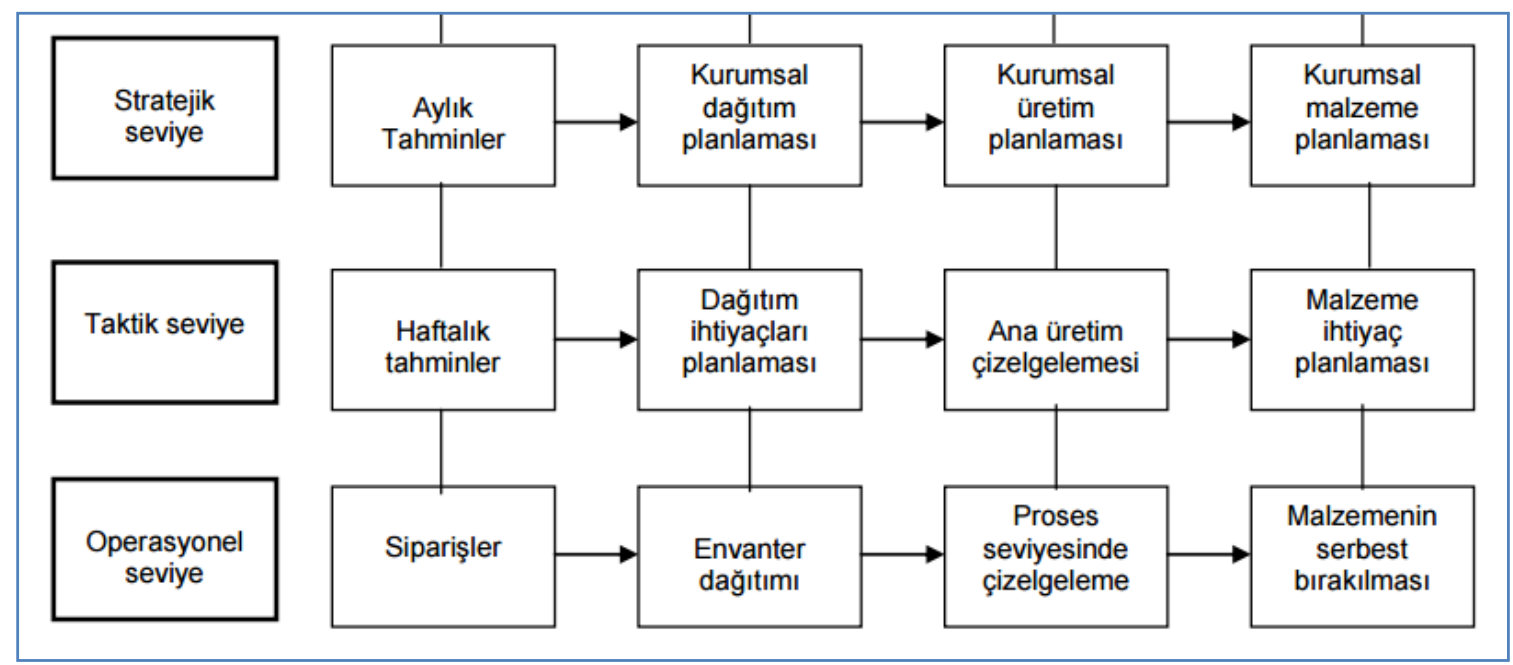

Şekil 3. Proje Yönetim Fonksiyonları (Project Management Functions) (Ilıcalı 2014)

Bu bir proje yönetim modeli olarak değerlendirilecek olursa Şekil 4 üzerinden açıklanabilir.

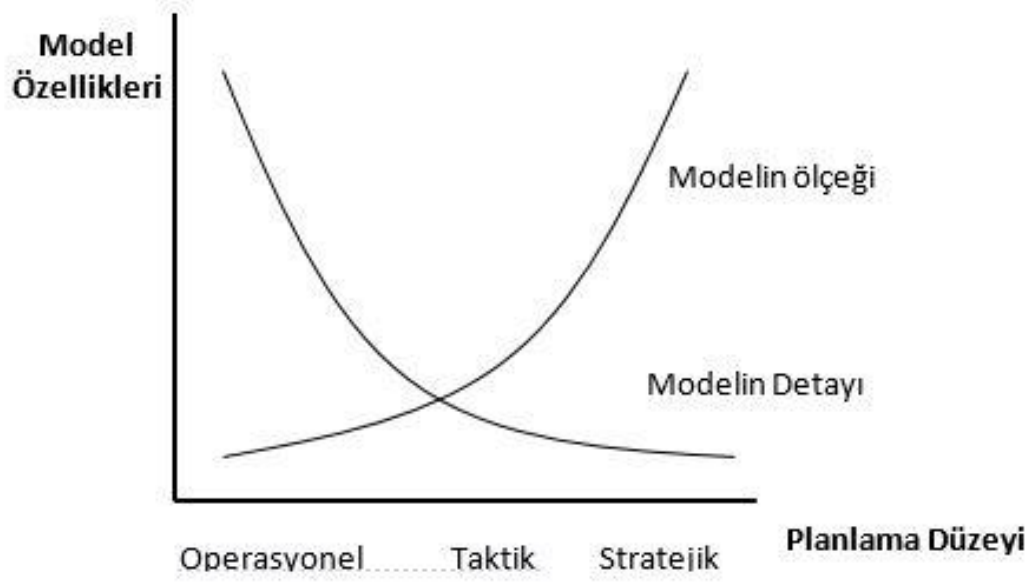

Şekil 4. Proje Yönetim Modelinde Planlama Düzeyleri (Project Management Model Planning Levels) (Ilıcalı 2014)

$\mathrm{Bu}$ anlamda ulaştırma yatırımları da sahip oldukları özellikler itibariyle operasyonel, taktik ve stratejik düzeyleriyle ele alınabilmektedir. Söz gelimi; yeni bir yüksek katlı (gökdelen) ya da büyük açıklıklı (alışveriş merkezi: AVM) yapının inşa edildiği bölgede trafik tıkanıklığının artması durumunda kısa vadeli ve çözüm odaklı bir proje geliştirilmesi gerekmektedir. Böyle bir durumda yapılan müdahale ele mevcut karayolu şerit eklenmesi, ilave sinyalizasyon tedbirleri ya da bir kavşak inşası operasyonel ulaştırma yatırımlarına girmektedir. Veya; yaya güvenliği ve erişilebilirliğine paralel olarak bir metro istasyonu ile bir devlet binası, etkinlik merkezi, alışveriş yeri, okul vs. arasına yapılacak olan bir yaya üstgeçidi yada yaya altgeçidi de operasyonel bir ulaştırma yatırımıdır.

Sosyal İskonto Oranları (SDR) ve Ferdi Bazlı Sosyal Fırsat Maliyetleri (SCOC), zamanı bağlı olarak mal varlığı ve değerleme etkilerindeki değişimi göstermektedir. Örneğin birçok ulaştırma yatırımı gelecek on yıllara yayılı fayda 
ve maliyetlere haiz birer miras projeleridir. İskonto oranları belirli bir proje ya da belirli bir tür etkilere bağlı riskleri yansıtmak üzere uyarlanabilmektedir. Söz konusu analizlere bağlı olarak bu iskonto oranları düşük riskli projeler için $\% 6,0$ ve büyük riskli projeler için ise de $\% 8,6$ olarak kabul edilebilir. İklim değişimi ve yaşam alanı kaybı gibi etkilerse yüz yıllara yayılı mali etkiler olușturabilecektir. Şehirleşmede, en önemli olgulardan bir tanesi yerleșim alanları, iş alanları, sanayi alanları ve diğer etkinlik alanlarının sınırlarının planlı bir şekilde belirlenmesi ve bütün planlamalarda bu sınırlara azami ölçüde riayet edilmesidir. Bu; planlamanın sürdürülebilirliği açısından büyük öneme sahiptir. Ancak bu çerçevede, ulaşım planları ve imar planlarının eşgüdümlü ve birbirini olumlu yönde besleyen şekilde geliştirilmesi sağlanabilmektedir. İstanbul başta olmak üzere Türkiye'deki șehirlerin ana problemi de bu konulardaki eşgüdüm ve entegrasyon eksikliğidir. Yerleşim yeri ve iş yeri seçimlerinin ulaştırma sistemine, bileșenlerine, kullanıcılara ve șehirleşmeye önemli etkileri söz konusudur. Bu etkiler, kullanıcıya ve genel olarak halka doğrudan ya da dolaylı maliyetler olarak yansımaktadır. Esasen üretkenliğin yerelleşmesi ve yenilikçi etkinlikler yolu ile kentler, kendilerini çevreleyen coğrafi alanı da şekillendirmektedir. İstihdam fırsatlarının uygunluğu ve hem tamamlayıcılık ve hem de rekabetçilik anlamındaki ortak girişimlerin mevcudiyeti, ev-iş yolculuk akımlarının doğrultusunu ve boyutunu belirleyecektir. Bilgi ve bilim insanlar içerisinde şekillendiği ölçüde, bu durum bilimin akışına yakın bir hizmet verecektir. 2006 yılında Karlsson ve arkadaşlarının çalışmasını takiben, bu tarz çalışmalar kapsamında işletimsel erişilebilirlik ölçütlerinin kullanımının incelenmesi yolu ile yersel yakınlığın kullanımının ötesine geçilmesi hedeflenmektedir. Bu durum; kentlerin içerisindeki ve dışarısındaki farklı varış noktalarına verili seyahat süreleri dâhilinde seyahat etmek için çalışan isteklerindeki (oldukça farklı meskûn mahallerden) anlayışı sağlayabilmektedir. Seyahat süresi verilerinin, ağ bağlantısallık yapısını yansıttı̆̆ı da not edilmelidir. Bu bağlamda; iş fırsatlarına ağ erişilebilirliklerini şekillendirdikleri gibi kişilerin kararlarının çıktıları olan kümeli emek pazarlarına odaklanılacaktır.

\section{Araştırma Bulguları (Research Findings)}

Geçmişte kentlerin tek merkezi bulunmakta olup kentin önemli etkinlik kollarının çoğu bu merkezde az bir kısmı ise alanlarına göre münhasıran seçilen çeşitli noktalarda toplanırdı. Söz gelimi İstanbul'da dahi Eminönü alış veriş merkezi, Şişli ve çevresi ana kentsel iş merkezi, Kadıköy Anadolu yakasının merkezi, Bakırköy ve ötesi sayfiyelik, kentin kuzey bölümleri (Şile, Beykoz, Eyüp) orman alanları olarak teşekkül etmişti. Günümüzde ise büyük kentler çok merkezli yapılara dönüşebilmektedir, alış veriş, eğitim, sağlık, gıda gibi birçok ana ihtiyaç ise kentin her merkezinde ve hatta hemen her noktasında bulunabilmektedir. İstanbul günümüzde tam birçok merkezli yapıya örnektir, öte yandan onlar AVM, onlarca üniversite, onlarca hastane vb. yapıya ev sahipliği yapmaktadır (Kızltaş 2018). Genelde bilinmektedir ki çalışan insanların yaşayacağı yer seçimi işyerlerine yakında olma isteğinden çok daha ziyadesi ile hayat kalitesi ve yaşam çevresi gibi unsurlardan etkilenmektedir. Bu da nispeten yüksek düzeyde ön plana çıkan ev iş yolculukları tarafından desteklenmektedir. Almanya'da işçilerin yaklaş̧k \%60'lık bir kısmı ki 17 milyon kişiye tekabül etmektedir sosyal sigorta dâhilinde iken bunlar yaşadıkları kentte çalışamamaktadırlar. İşe ulaşmak için çalışan insanlar her gün ortalama yarım saat zaman harcamaktadırlar. Araç kullanımı burayı domine etmekte olup \%66'lardadır, Amerika Birleşik Devletleri'nde bu oran en yüksek \%86'dır. İstihdam ve işgali kapsayan veri dizilerine dayalı olaraktan bölgesel sınırlar boyunca Guth ve arkadaşları son on yıllarda Almanya'daki kümeli alanlarda gelişen mesafe kapsamı ve evin bulunduğu kentin ötesinde ev iş yolculuğu oranlarını tayin etmiştir. Günden güne teknolojik olarak ilerleyen toplum tecrübesi göstermektedir ki risk ve riskli davranışlar hayatın önlenemez birer parçasıdır. Belirsizlik ve ölçülemezlik artık daha uzun süre görülmeyecektir zira az ya da çok hesaplanabilir belirsizlikler vahim olaylara neden olabilir. Bunun bir sonucu ise yeni teknoloji üreticileri için risk yönetimini ifade eden daha yüksek taleplerdir. Bütün muhtemel kısıtlar dikkate alınmak sureti ile tehlikenin yapısal bir analizi potansiyel bir tehlikenin bir başlangıç incelemesinin gerçekleştirilmesine yardımcı olabilir. Dolayısı ile erken gelişim aşamalarında mantıki tehlike analizi ve bilahare risk tasnifinin temini için otomat araçların sınıflandırılmasının tamamlanmasını sağlama adına bir hassasiyet geliştirmektedir.

Bu esasa temellendirmek sureti ile bir disiplinler arası uzman ekibi için bir projenin en gelişmiş hali üzerindeki potansiyel tehlike durumlarının liste haline getirilebilir olması bir kapasiteye işaret etmektedir. Bu da genellikle bir dizi bağlantılı hususa neden olmaktadır. Pratik değerlendirmelere dayalı olaraktan uzman görüşü ve çeşitli testler dâhilindeki senaryolar bilahare en bağlantılı olanlarla sınırlandırılmalıdır (Altan ve Kızıltaş 2018). Bunun dâhilinde güvenlik gereksinimlerinin 'ne kadar güvenlik yeterli güvenliktir' anlayışı dâhilinde cevaplanması gerekmektedir. Uzman deneyimi aynı zamanda kabul edilebilir riskler için güvenlik artışı ve tüketici beklentilerini karşılamak adına kati surette destek sağlamaktadır. Artan tüketici taleplerinin ışığı altında, özellikle de önceki ürün sorumluluk etkinlikleri dâhilinde bu gibi bir deneyim, gelişim ve onay aşamaları boyunca ürün güvenliğinin arttırılmasına değerli bir katkıda bulunmaktadır (Rawat, 2016). Bu bağlamda muhtelif projeler için genel inşaat, planlama ve işletim maliyetleri çıkartılmış ve karşılaştırılmıştır. Şekil 5'te örnek bir proje 1 için şantiye, üretim, satış, yönetim vb. hususların maliyetten aldıkları paylar bağlamındaki bir karşılaştırması verilmektedir. $\mathrm{Bu}$ bağlamda Şekil 6'da ise söz konusu inşaat maliyetlerinin kalem bazında ağırlıkları ortaya konulmuştur.

İnşaat faaliyeti esnasında hesaba katılan dolaylı sabit maliyetler söz konusudur. Bunların da hesaba katılması ile birlikte ancak tam ve doğru bir fayda maliyet analizi çıkarılmış ve doğru karara zemin hazırlanabilmiş olacaktır. 
Bunlar; bakım onarım, betonun temin edildiği santral, mühendislik şirketinden alınan proje hesap ve çizim desteği, harici faydalar (enerji sağlanması vs.), amortisman değerleri gibi başlıklar altında derlenebilecek oldukça önemli hususlar ve hesap kalemlerine işaret etmektedir. Kapsamlı bir değerlendirme ve çok yönlü bir şekilde bütün girdi çıktıların analize dâhil edilmesi marifeti ile ancak doğru ve net bir sonuca ve karar yeterliliğine ulaşılabilecektir. Şekil 7'de ilgili detaylar ortaya konulmuştur.

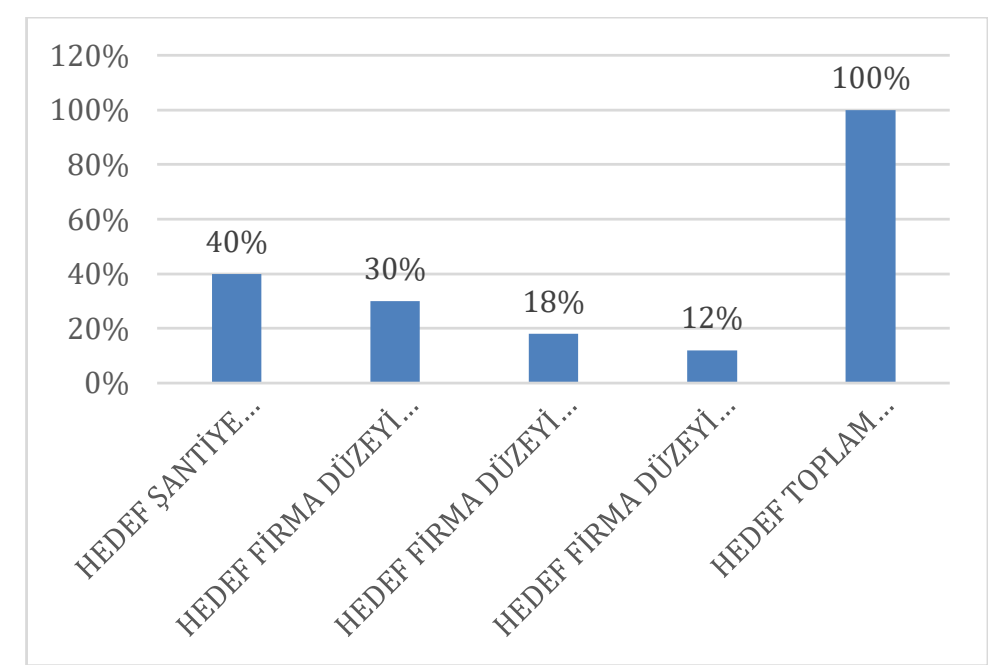

Şekil 5. Örnek Bir Yapı İçin İlgili Maliyetlerin Oranlı Bir Dağılımı (Related Costs’ Proportional Distribution For A Sample Building) (Kuruoğlu 2006)

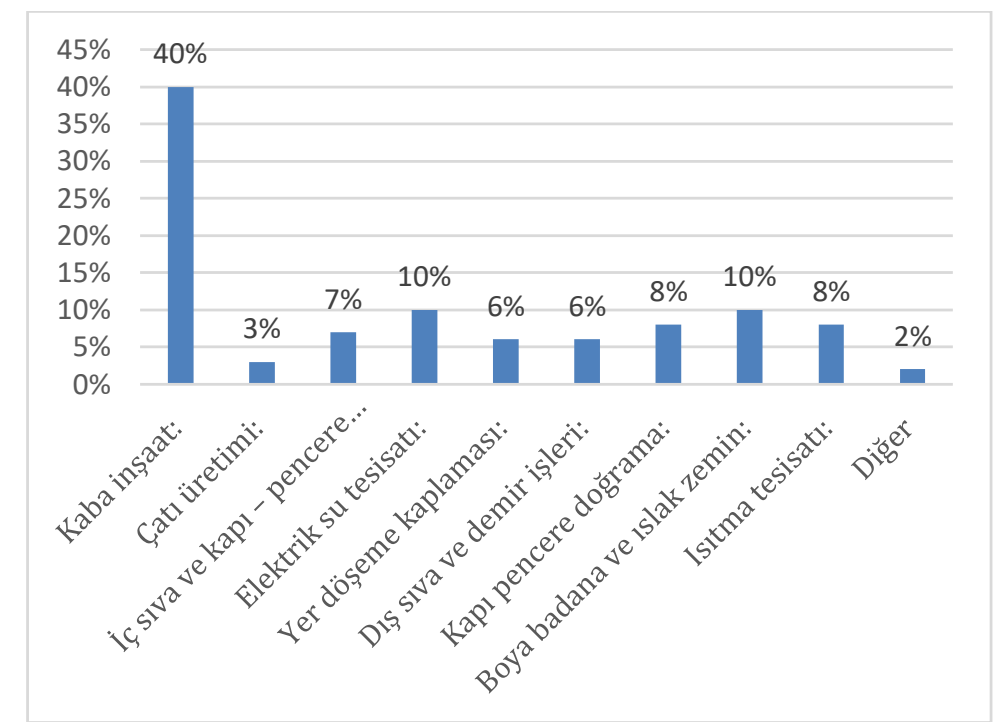

Şekil 6. Detaylı İnşaat Maliyet Kalemleri (Detailed Construct Cost Items) (Pazarçeviren 2020) 


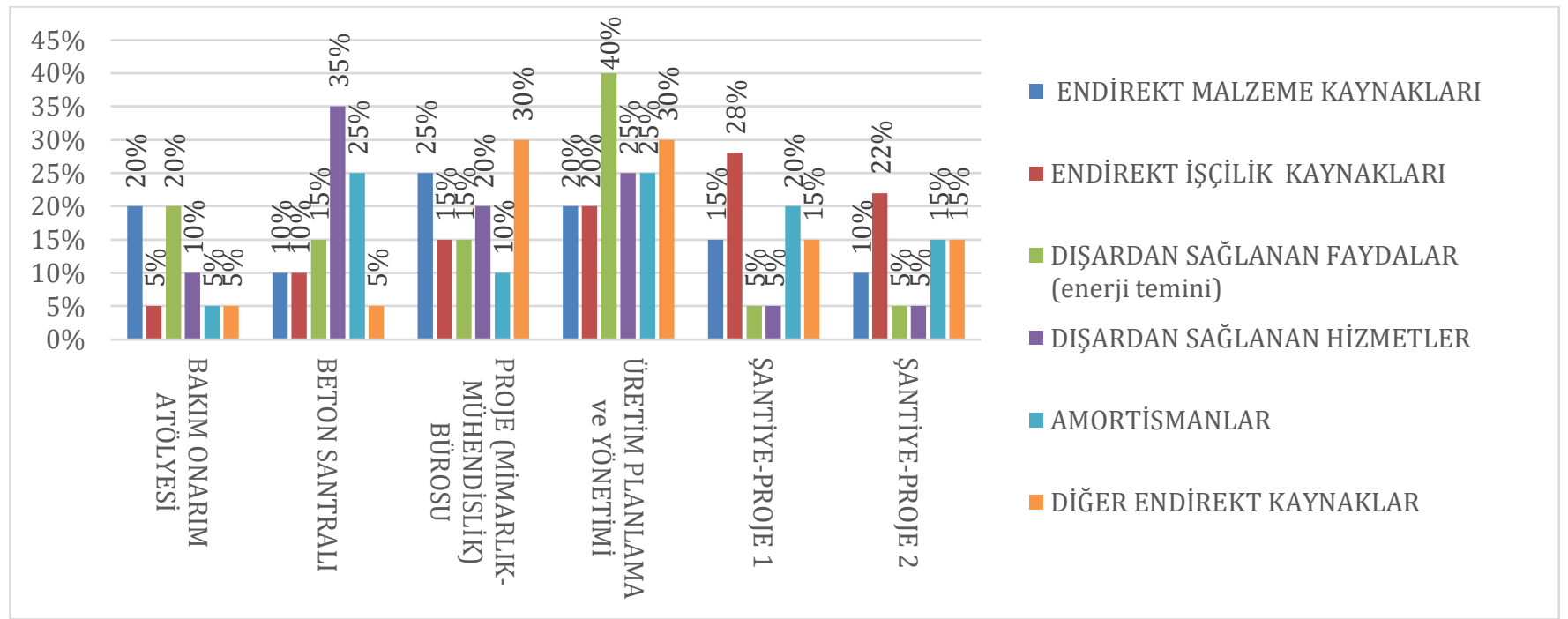

Şekil 7. İnşa Faaliyetlerinde Dolaylı Sabit Maliyetler (Indirect Cosntant Costs On Construction Activities) (Pazarçeviren 2020)

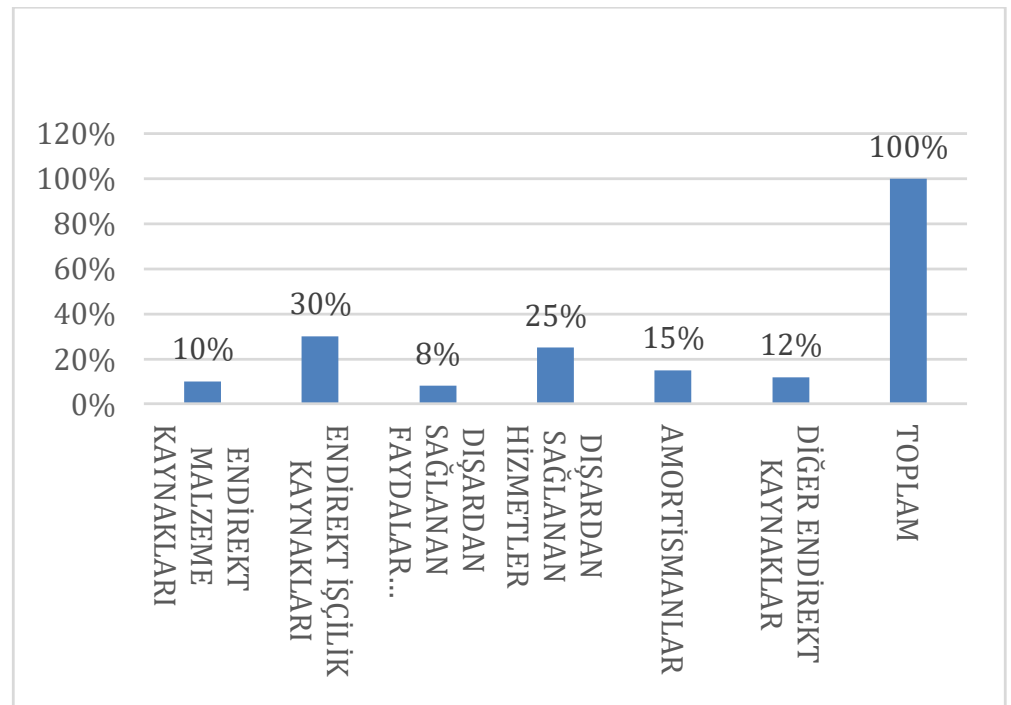

Şekil 8. Süreçteki Fayda ve Maliyetler (Costs and Benefits on Process) (Pazarçeviren 2020)

Süreçte daha önce belirtildiği üzere hem faydalar hem maliyetler ve hem de her iki ana tasnifin hesaba katılması sureti ile elde edilen ve neticesinde yatırım yapmak ya da yapmamak yönündeki karara yönlendiren bir fayda maliyet analizi söz konusu olmaktadır. Şekil 8'de buna ilişkin detaylara yer verilmektedir. Şekil 9'da ise bu durum daha detaylı alt kalemler dâhilinde ortaya konulmuştur. Kentsel arazi kullanımının gelişimi bu senaryoda farklı bir şekilde tanımlanmaktadır. Bir tarafta yüksek oranda yoğunlaşmış kentler olacak olup diğer taraftan ise indirgenmiş yoğunluklu alt kentler ise büyüyecektir. Özellikle de genç insanlar kent merkezlerinde yaşamayı tercih edecek iken bir diğer taraftan ise artan sayıdaki yüksek gelir gurubu ise kırsal alana ya da kent mücavir alanına doğru hareket edecek gibi görünmektedir. Kent merkezindeki işlerine artan mesafelerine karşın gerek uygun otomat aracın kullanımı ve gerekse de daha güçlü iletişim araçlarını kullanan tele bulunma (sanal gerçeklik) desteği ile yoğun iş hayatlarına devam edebileceklerdir. 


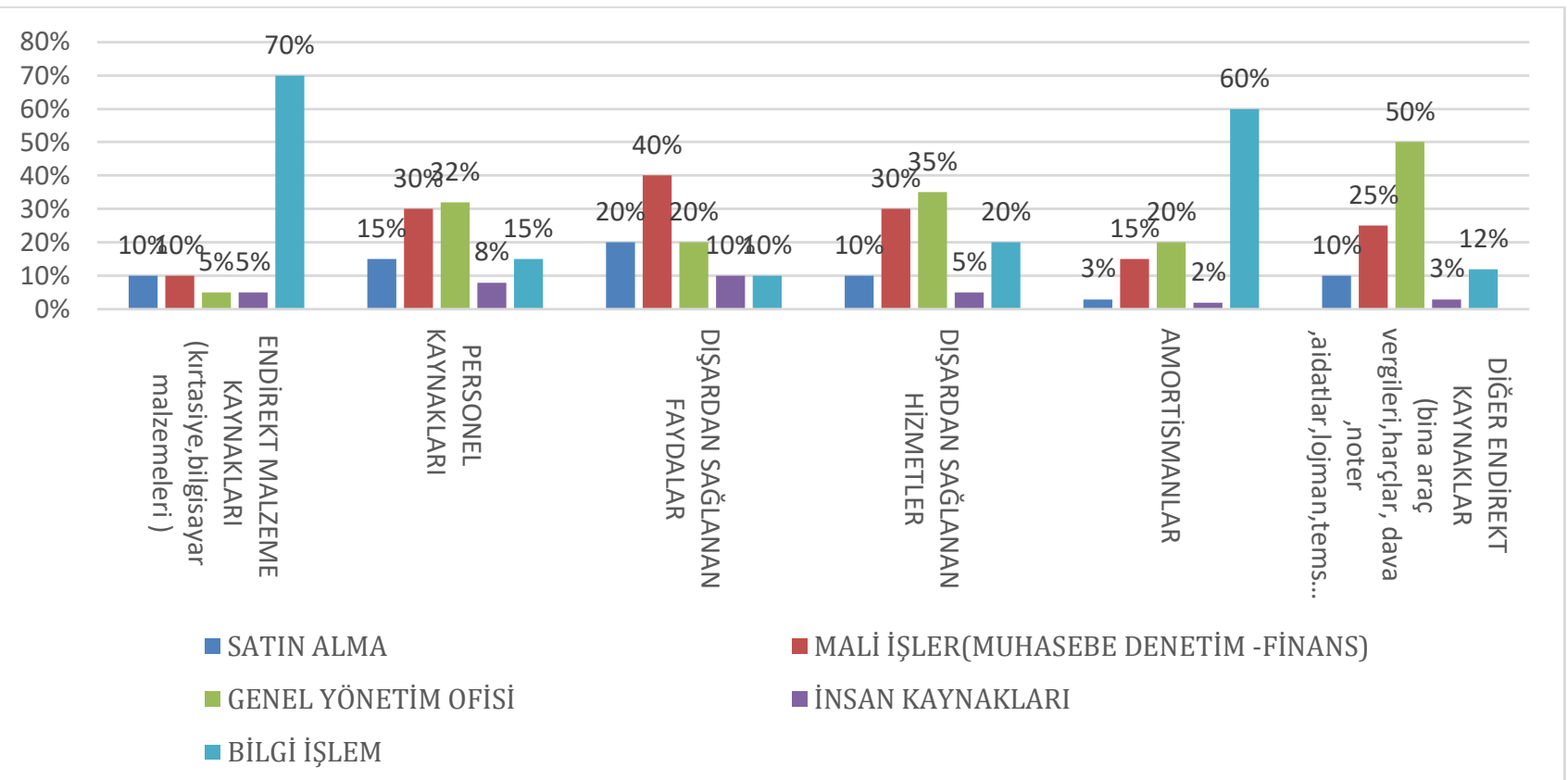

Şekil 9. Endirekt Sabit Maliyet Detayları (Costs and Benefits On Process) (Pekgökgöz vd., 2007)

Aynı zamanda alt kent alanlarında (banliyö, kenar mahalle) yaşayan söz konusu bu nüfus grubu ise hiper hareketli dünyada artan bir şekilde eziyetli ve çetin bir iş hayatını karşılayabilme imkânına sahip olabileceklerini düşünmeye bașlayacaklardır (Kanıt ve Baykan, 2004). Yenileyici ve hiper hareketli kentler, kentsel hayati hareketlilik ve kent yapısındaki değişimler için bir motor olaraktan teknolojik gelişimleri aydınlatır iken bir diğer taraftan ise söz konusu bu senaryo biraz daha farklı bir tablo çizecektir (Spaven, 2006). Burada teknolojik yenilik ile ilgili olaraktan altı çizilen kabuller, özellikle de gerek duyulan altyapının yüksek maliyetlerine bağlı olaraktan büyük bir gelişim göstermemişlerdir. Teknolojik gelişme söz konusudur ancak bu temelde belirli alanların verimlilik kazanımları ile sınırlandırılmış vaziyetteki bir hususu teșkil etmektedir. Kalkınma çarkını döndürmek adına söz konusu bu durumun gücü ise sınırlı görünmektedir. Hatta davranıștaki bir dönüşüm yukarıdaki gelişimde de tasarlandığı üzere, görülmeyecektir. Emek pazarlarının sadece yerel etkinliklere bağlanan izole (ayrık) pazarlar olmadığı da vurgulanmalıdır. Bunlar; her birisi birbirini etkileyen (örneğin ev iş yolculuk akımları vasıtası ile) bağlantılı pazarların bir ağı olarak șekillenmekte ve yerel ekonomideki gelişmeler ile sosyo ekonomik kuvvetlerin rekabetinin ortaya çıkması yolu ile yüksek dereceli dalgalanmalar sergileyebilir (Takatsu, 2007). İș fırsatlarının (ya da iş erişilebilirliği) yakınlığı, elbette ki bir emek pazarları ağının gelişiminde önemli bir faktördür. Ve dahası, birbirine bağlanan emek pazarlarının (rekabetçi ve tamamlayıcı) daha kapsamlı bir ağ kümelenmesinde yerel/bölgesel emek pazarlarının konumunun daha etraflıca incelenmesi de kritik bir önemde olmaktadır (Ptuhina vd., 2015). Esasen son birkaç on yılda, bölgesel bilim ve coğrafi literatürde ağ muhtevaları ile ilgili artan bir ilgiye şahit olunmuştur (Román vd., 2010). Ağlar; dâhil olan aktörlerce kabul edilen (doğrusal olmayan ve dinamik etkinlik kümelenmelerini içeren) çeşitli merkezcil ve merkezkaç roller dâhilindeki organize etkinliklerin karmaşık bir etkileşim sistemi şeklinde tasarlanmıştır. Bu perspektiften, yakın dönem bölgesel ekonomik araştırmalarındaki karmaşık yersel ağların gelişimi ve yapının planlanmasında analitik bir bağıntı elde edilebilmektedir. Konutların yer seçimi, konut satışları, arazi fiyatı ve değerlenmeleri, yerleşim yerinin oluşumu gibi hususlarda yukarıda belirtilen noktaların önemli bir payı bulunmaktadır. Așağıda şekilde Türkiye için güncel konut satış sayıları Mayıs 2020 tarihi itibari ile verilmiş olup önceki iki yıla nazaran deprem, ekonomik veriler, salgın ve benzeri çok önemli hususlara bağlı olaraktan düşük seyretmektedir. Ancak esasen 2020 yılının ilk 3 aynın her şeye rağmen önceki 2 sene ile benzer seviyelerde seyrettiği ancak Nisan 2020 ve Mayıs 2020 dönemlerinde konut satışlarında ciddi azalmalar gerçekleştiği görülmektedir. Bu da özellikle COVID 19 salgını ile ilintili bir konunun öne çıtığı tezini güçlendirmektedir. 


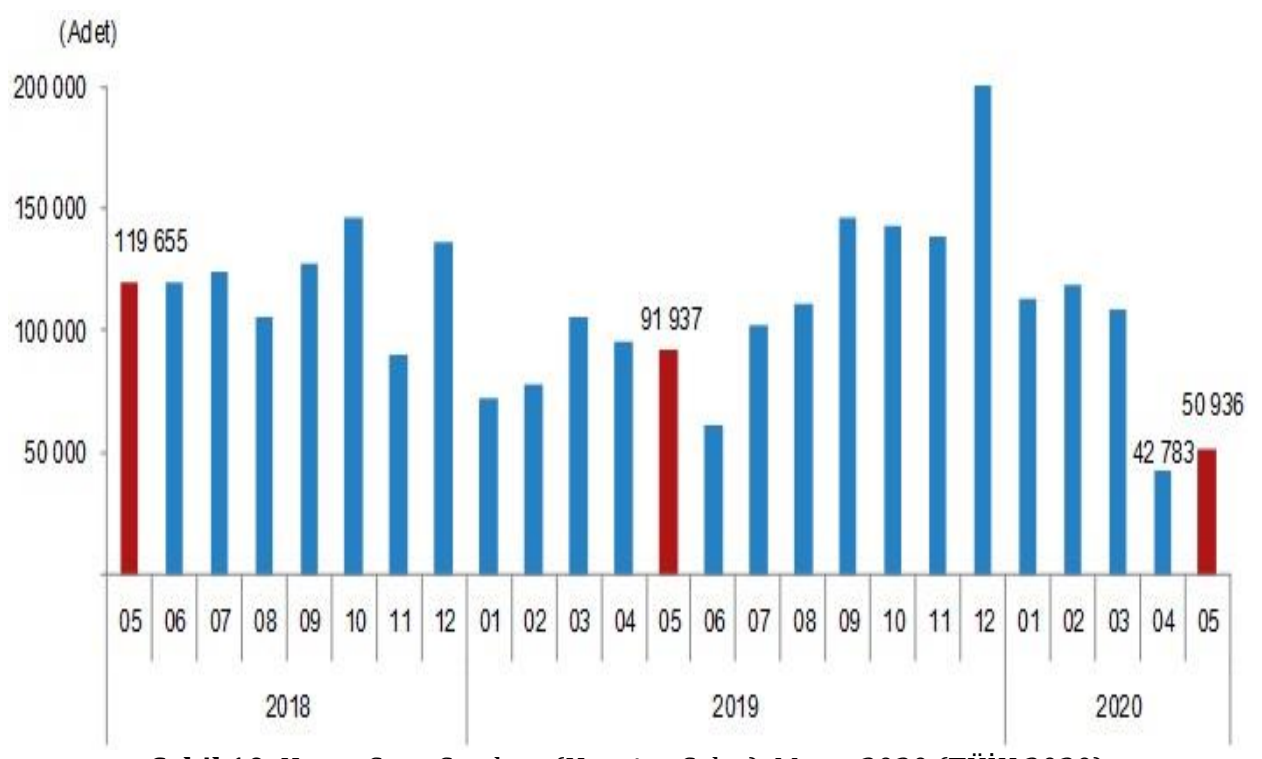

Şekil 10. Konut Satış Sayıları, (Housing Sales), Mayıs 2020 (TÜİK 2020)

\section{Sonuç ve Tartışma (Result and Discussion)}

Ekonomik etkinliklerin yersel kümelenmesi, yoğunluk ve ağ kümelenme avantajları ekonomisinin bir sonucu olarak sıklıkla bilimsel literatürde gözlemlenmektedir (Ureña, vd., 2009). Bu bağlamda 2007 yılında Russo ve arkadaşlarının ifadesi şu șekildedir 'kentler girișimci etkinliklerin katalizörleridir (hızlandırıcı) çünkü girişimci etkinlikler bir vakumla (basınç) ortaya çıkmazlar (Duvanova ve Simankina, 2016). Esasen diğer benzeri girișimcilere yakınlığın yanı sıra bilgi ekonomisindeki girișimciler; finansal hizmetler, yüksek eğitimli iş gücü, bilgi kaynakları (üniversiteler ve araștırma merkezleri), lojistik hizmetler vs. gibi bir dizi tamamlayıcı hizmeti gerektirmektedir. Bir dizi yakın dönem çalışması, mücavir alan etkisini tasdiklemektedir' (Combes vd., 2008). Kümelenme ve ekonomik büyüme kapsamında kentlerin merkezi rolü aynı zamanda diğer çalışmalarca da teşvik edilmektedir (Department for Transport, 2011) 2000 yllında Duranton ve arkadaşları şunları ifade etmiştir 'Kent sadece büyümenin ortaya çıktığı yer değil ve fakat aynı zamanda da bizatihi büyümenin itici gücüdür'. 2008 yılında ise Nijkamp 'İș hayatı ve kent arasındaki ilișki çoğu zaman, kentsel ekonomi altında temsil edilmektedir fakat tam ölçekli bir dikkat gerektirmektedir' ve 1998 yllında ise Quigley 'Büyük kentler önemli bir ekonomik büyüme kaynağı olagelmiştir ve olmaya da devam edecektir' demiştir (Wong vd., 2002). Bunun hemen hemen tersine 2005 yllında Polèse ekonomik büyümeyi açıklayan sosyo ekonomik süreçlerin birincil olarak kentsel düzeyde değil ulusal ve toplumsal düzeyde işletildiğini değerlendirmektedir. Bu araștırmacı, kümelenme ve ekonomik büyüme arasındaki ilişkinin titizlikle sınanmasının zorluğuna işaret etmektedir (Bureau of TSRIT Administration, 2011).

İnşaat maliyetleri son yıllarda Türkiye'de dövize bağlı artışlar göstermesine karşın halen oldukça karşı bir sektördür. Türkiye'deki ekonominin ana dişlilerinden bir tanesini teşkil etmektedir. Ülkede konut ihtiyacı sürekli devam eden kentleşme ve de ilaveten kentsel dönüşüm bağlamında artarak devam etmektedir. Kentleşme temelli sorunlar, depreme karşı yapılan hazırlıklar ve halkın ihtiyaçları iyi analiz edildiği takdirde yeni sektörel atılımlar beklenen bir durumu teşkil edecektir. Ancak bu kez aynı zamanda daha derinlikli çözümleri de beraberinde getirecektir.

\section{Teşekkür (Acknowledgement)}

Bütün değerli hocalarımıza teșekkür ederiz.

\section{Çıkar Çatışması (Conflict of Interest)}

Yazarlar tarafından herhangi bir çıar çatışması beyan edilmemiştir. No conflict of interest was declared by the authors.

\section{Kaynaklar (References)}

Altan, M.F., Kızıltaş, M.Ç., 2018, Toplu Taşımada Çok Amaçlı Karar Verme ve Metropolitan Bir Alanda Ev-İş̧ Ulaşım Hizmeti Modellemesi, Karaelmas Fen ve Mühendislik Dergisi, ULAKBİM

Bureau of Transportation Statistics, Research and Innovative Technology Administration, 2011. Key Transport Indicators 
Combes, P. P., Mayer, T., \& Thisse, J. F. (2008). Economic geography: The integration of regions and nations. Princeton University Press.

Rawat, D. B., Rodrigues, J. J., and Stojmenovic, I., Cyber-Physical Systems: From Theory to Practice. CRC Press, 2015.

D. B. Rawat, Adaptive Connectivity, Security and Privacy in Transportation Cyber Physical Systems. Springer, 2016.

Department for Transport, 2011. High Speed Rail: Investing in Britain's Future. http://www.dft.gov.uk/pgr/rail/pi/highspeedrail/ (viewed 20.04.11).

I.A. Duvanova, T.L. Simankina, Optimization of the conditions of parking space residential buildings. Construction of unique buildings and structures. 2016. 2 (41). pp 108-117.

Ilıcalı, M., 2014, 'Şehiriçi Ulaşımda Yenilikçi Uygulamalar, AUS ve Parklanma Uygulamaları - 2' http://www.tasimadunyasi.com/sehirici-ulasimda-yenilikci-uygulamalar-aus-ve-parklanma-uygulamalari-2makale,317.html (01.11.2014)

Ilıcalı, M., Camkesen, N., Kızıltaş, M.Ç., Ekinci, B., 2014, 'İstanbul' da Ulaştırma Sisteminde Türlerarası Entegrasyon ve Boğaz Geçișleri', 5.Karayolu Trafik Güvenliği Sempozyumu ve Sergisi, Ankara

Kanıt R., Baykan U.N. Bina Yaklaşık Maliyetinin Çoklu Doğrusal Regresyon ile Belirlenmesi, 2004.

Kızıltaş, M, Ç, 8-10 Kasım 2018, Küresel Örnekleri ile Toplu Ulaştırma, Transist 2018, İstanbul Ulaşım Kongresi ve Fuarı, İstanbul

Kuruoğlu, M. (2006). Konut Amaçlı Arazi Yatırımlarında Fizibilite ve Pratik Bir Metot Önerisi, İTO yayınları

Liu, Y., Zhang, X., Zeng, J., Zhang, X., Zhang, P., \& Zhong, Z. 2007. Technology of Sound Intensity Theory in High Speed Railway Car Noise Controlling. In International Conference on Transportation Engineering. pp. 1243-1248.

Pekgökgöz, K., Gürel, M., Kömür M , Çlı F. (2007). Cost Analysis of A Building With Seismic Base Isolation System, Sigma Dergisi

Ptuhina I., Spiridonova T., Musorina T. Performance evaluation of high-rise complex construction depending on building site placement. Applied Mechanics and Materials. 2015. Vol. 725-726. Pp. 153-159.

Román, C., Espino, R., \& Martín, J. C. (2010). Analyzing competition between the high speed train and alternative modes: The case of the Madrid-Zaragoza-Barcelona Corridor. Journal of Choice Modelling, 3(1), 84-108.

Spaven, D. 2006. Are High-speed railways good for the environment. Transform Scotland, Edinburgh, 3.

Takatsu, T. 2007. The history and future of high-speed railways in Japan. Japan Railway \& Transport Review, 48, 6-21.

T.C. 10.Kalkınma Planı Ulaştırma ve Trafik Güvenliği Ö.İ.K. Raporu, 2012, Ankara

Ureña, J. M., Menerault, P., \& Garmendia, M. (2009). The high-speed rail challenge for big intermediate cities: A national, regional and local perspective. Cities, 26(5), 266-279.

Wong, W. G., Han, B. M., Ferreira, L., Zhu, X. N., \& Sun, Q. X. (2002). Evaluation of management strategies for the operation of high-speed railways in China. Transportation Research Part A: Policy and Practice, 36(3), 277-289. 